\title{
Ethanol Inhibits Clearance of Brain Serotonin by a Serotonin Transporter-Independent Mechanism
}

\author{
Lynette C. Daws, ${ }^{1}$ Sylvia Montañez, ${ }^{1}$ Jaclyn L. Munn, ${ }^{1}$ W. Anthony Owens, ${ }^{1}$ Nicole L. Baganz, ${ }^{1}$ Janel M. Boyce-Rustay, ${ }^{2}$ \\ Rachel A. Millstein, ${ }^{2}$ Lisa M. Wiedholz, ${ }^{2}$ Dennis L. Murphy, ${ }^{3}$ and Andrew Holmes ${ }^{2}$ \\ ${ }^{1}$ Department of Physiology, University of Texas Health Science Center at San Antonio, San Antonio, Texas 78229-3900, ${ }^{2}$ Section on Behavioral Science and \\ Genetics, Laboratory for Integrative Neuroscience, National Institute on Alcohol Abuse and Alcoholism, Bethesda, Maryland 20892, and ${ }^{3}$ Laboratory of \\ Clinical Science, National Institute of Mental Health, National Institute of Health, Bethesda, Maryland 20892
}

Brain serotonin (5-HT) modulates the neural and behavioral effects of ethanol in a manner that remains poorly understood. Here we show that treatment with physiologically relevant (i.e., moderately intoxicating) doses of ethanol inhibits clearance of 5-HT from extracellular fluid in the mouse hippocampus. This finding demonstrates, in vivo, a key molecular mechanism by which ethanol modulates serotonergic neurotransmission. The 5-HT transporter (5-HTT) is the principle means of 5-HT reuptake in the brain and an obvious candidate mechanism for the effect of ethanol to inhibit 5-HT clearance. However, our second major finding was that genetic inactivation of the 5-HTT in a knock-out mouse not only failed to prevent ethanol-induced inhibition of 5-HT clearance, but actually potentiated this effect. Ethanol-induced inhibition of 5-HT clearance was also potentiated in nonmutant mice by cotreatment with a 5-HTT antagonist. Providing a link with potential behavioral manifestations of this neural phenotype, 5-HTT knock-out mice also exhibited exaggerated sensitivity to behavioral intoxication, as assayed by the sedative/hypnotic effects of ethanol. This clearly demonstrates that the 5-HTT is not necessary for the neural and behavioral effects of ethanol observed herein and that genetic or pharmacological inactivation of the 5-HTT unmasks involvement of other principle mechanisms. These data are intriguing given growing evidence implicating the 5-HTT in the pathophysiology and treatment of alcoholism and neuropsychiatric conditions frequently comorbid with alcoholism, such as depression. The present findings provide new insights into the actions of ethanol on brain function and behavior.

Key words: 5-HT; serotonin transporter; gene; alcohol; clearance; mouse

\section{Introduction}

Alcoholism is one of the most burdensome of neuropsychiatric disorders in modern society yet remains poorly understood and ineffectively treated (Volkow and Li, 2004). Across species, ethanol has potent effects on neural function that lead to marked changes in affect, cognition, and motor function (McBride et al., 1993; Virkkunen and Linnoila, 1997). Studies in rodents have shown that ethanol significantly elevates extracellular levels of forebrain serotonin (5-hydroxytryptamine; 5-HT) a neurotransmitter system involved in the mediation of these behaviors (McBride et al., 1993; Le Marquand et al., 1994; Thielen et al., 2001). These effects of ethanol on 5-HT have been posited as an important mechanism by which ethanol produces its neural and behavioral effects. However, the nature of this relationship remains to be fully elucidated.

Received Sept. 23, 2005; revised April 28, 2006; accepted April 28, 2006.

This work was supported by National Institute of Mental Health Grant R01-MH64489 to L.C.D., National Alliance for Research on Schizophrenia and Depression grants to L.C.D. and A.H., and by the National Institute on Alcohol Abuse and Alcoholism-Intramural Research Program (IRP) (J.M.B.-R., R.A.M., L.M.W., A.H.) and National Institute of Mental Health-IRP (D.L.M.). We thank Drs. Ting Kai Li, David Lovinger, and Glenn Toney for their critical evaluation of a previous version of this manuscript, and to Rebecca Horton for expert technical assistance.

Correspondence should be addressed to Lynette C. Daws, University of Texas Health Science Center at San Antonio, Department of Physiology, 7703 Floyd Curl Drive, MC 7756, San Antonio, TX 78229-3900. E-mail: daws@uthscsa.edu.

DOI:10.1523/JNEUROSCI.4050-05.2006

Copyright $\odot 2006$ Society for Neuroscience $\quad$ 0270-6474/06/266431-08\$15.00/0
Serotonin neurotransmission is tightly controlled by highaffinity uptake of 5-HT by the 5-HT transporter (5-HTT). Blockade of the 5-HTT significantly increases extracellular levels of 5-HT (Fuller and Wong, 1990; Blakely et al., 1998). As such, antagonism of 5-HTT function by ethanol represents a strong candidate mechanism for ethanol-induced increases in extracellular 5-HT. Further supporting a functional relationship between ethanol and the 5-HTT, there is growing evidence of abnormal 5-HTT function in alcoholism and in animal models of the disease. For example, significant reductions in 5-HTT binding have been found in the living and the postmortem brains of alcoholics (Heinz et al., 2000; Kranzler et al., 2002). In addition, a polymorphism in the promoter region of the human and nonhuman primate 5-HTT gene, which confers low-expression of 5-HTT, has been associated with alcoholism and certain neuropsychiatric disorders that are frequently comorbid with the disease, such as anxiety and depression (Thompson et al., 2000; Kranzler et al., 2002; Barr et al., 2004a,b). Together, these findings support a possible role for the 5-HTT in modulating the effects of ethanol on brain 5-HT and, further, suggest that the level of 5-HTT function or expression may impact the behavioral effects of ethanol (Roach et al., 1973; Daoust et al., 1985, 1991a,b; Le Marquand et al., 1994).

Here, we examine the role of the 5-HTT in mediating effects of ethanol on brain 5-HT and behavior. Using chronoamperom- 
etry, 5-HT clearance was measured in vivo in 5-HTT mutant mice and in nonmutant mice cotreated with a 5-HTT antagonist after either locally or systemically applied ethanol. These measurements were made in the hippocampus, a region in which ethanol is known to increase extracellular 5-HT as measured by microdialysis (Bare et al., 1998; Thielen et al., 2002), and in which 5-HT clearance has been studied extensively using chronoamperometry (Montañez et al., 2003; Daws et al., 2005). Results indicated a profound potentiation of the ability of ethanol to inhibit 5-HT clearance in 5-HTT mutant mice. Therefore, we also examined whether inactivation of the 5-HTT potentiated behavioral responses to ethanol. Because the hippocampus has been implicated in mediating the sedative/hypnotic effects of ethanol in rodents (Miyakawa et al., 1997; Yaka et al., 2003), we tested ethanol-induced sedation/hypnosis in 5-HTT mutant mice and in nonmutant mice treated with 5-HTT antagonists.

\section{Materials and Methods}

Animals. 5-HTT-/- mice were generated as described previously (Bengel et al., 1998). 5-HTT $+/-$ mice express 50\% fewer 5-HTTs than their wild-type $(+/+)$ littermate counterparts, and null mutants (5HTT-/-) show complete loss of 5-HTT expression (Bengel et al., 1998). As a result, 5-HT clearance is reduced in $5-\mathrm{HTT}+/-$ mice and greatly compromised or absent in 5-HTT-/- mice (Montañez et al., 2003; Perez and Andrews, 2005), and extracellular levels of 5-HT are approximately fivefold higher in $5-\mathrm{HTT}+/-$ mice and ninefold higher in 5 -HTT $-1-$ mice, as compared with 5 -HTT $+/+$ controls (Mathews et al., 2004; Shen et al., 2004). For the present study, male 5-HTT -/-, $+/-$ and $+/+$ mice on a congenic C57BL/6J background were littermates derived from 5 -HTT $+/-$ by $5-\mathrm{HTT}+/-$ matings and were raised and housed together in same-sex groups from weaning onwards in the same temperature- and humidity-controlled vivarium, under a $12 \mathrm{~h}$ light/dark cycle (lights on 6:00 A.M.). The effects of citalopram and fluoxetine on the sedative/hypnotic effects of ethanol were tested in separate ethanol-naive cohorts of male C57BL/6 J mice obtained from the Jackson Laboratory (Bar Harbor, ME) at 8-10 weeks of age and housed in groups of five mice/cage under the same conditions as described above. All procedures conducted on the animals were approved by the local institutional animal care and use committee and were in strict accordance with the National Institutes of Health Guide for the Care and Use of Laboratory Animals.

In vivo high-speed chronoamperometry. Carbon fiber electrodes (30 $\mu \mathrm{m}$ tip diameter) were coated with Nafion (5\% solution; Aldrich Chemical, Milwaukee, WI), to prevent interference from anionic substances in extracellular fluid as described previously (Daws et al., 1997, 2000). Electrodes were tested for sensitivity to the 5-HT metabolite, 5-hydroxyindoleacetic acid (5-HIAA, $250 \mu \mathrm{M})$ and calibrated with accumulating concentrations of 5-HT $(0-3 \mu \mathrm{M})$. Only electrodes displaying a selectivity ratio for 5-HT over 5-HIAA $>500: 1$ and a linear response $\left(r^{2}\right.$ $\geq 0.9)$ to 5 -HT were used. The detection limit for the measurement of 5 -HT was defined as the concentration that produced a response with a signal-to-noise ratio of 3 and in these experiments averaged $43 \pm 10 \mathrm{nM}$ $(n=103)$.

The electrochemical recording assembly consisted of a Nafion-coated, single carbon fiber electrode attached to a four-barreled micropipette such that their tips were separated by $\sim 200 \mu \mathrm{m}$. Barrels were filled with either 5-HT (200 $\mu \mathrm{M})$, ethanol (100 mM), or PBS. All compounds were prepared in $0.1 \mathrm{M}$ PBS with $100 \mu \mathrm{M}$ ascorbic acid added as an antioxidant and the $\mathrm{pH}$ adjusted to 7.4. Ethanol was tested in vitro before use and did not itself produce an electrochemical signal or influence the signal produced by 5-HT in vitro. The electrode-micropipette recording assembly was lowered into the $\mathrm{CA} 3$ region of the dorsal hippocampus (anteroposteriorly, -1.94 from bregma; mediolaterally, +2.0 from midline; dorsoventrally, -2.0 from dura) (Franklin and Paxinos, 1997) of anesthetized mice (see Fig. $1 A, B$ ). For all experiments, mice were anesthetized by intraperitoneal injection ( $2 \mathrm{ml} / \mathrm{kg}$ body weight) of a mixture of chloralose
(35 mg/kg) and urethane $(350 \mathrm{mg} / \mathrm{kg}$ ). A tube was inserted into the trachea to facilitate breathing and mice were then placed into a stereotaxic frame. The mice were supported by a raised foam platform to facilitate respiration. Body temperature was maintained at $36-37^{\circ} \mathrm{C}$ by a water-circulated heating pad.

High-speed chronoamperometric recordings were made using the Fast-12 system (Quanteon, Nicholasville, KY) (Montañez et al., 2003). Oxidation potentials consisted of $100 \mathrm{~ms}$ pulses of $+0.55 \mathrm{~V}$. Each pulse was separated by a $900 \mathrm{~ms}$ interval during which the resting potential was maintained at $0.0 \mathrm{~V}$. Voltage at the active electrode was applied with respect to a $\mathrm{Ag} / \mathrm{AgCl}$ reference electrode positioned in the extracellular fluid of the ipsilateral superficial cortex. The oxidation and reduction currents were digitally integrated during the last $80 \mathrm{~ms}$ of each $100 \mathrm{~ms}$ voltage pulse.

Because of adsorption of electrogenerated products at the electrode surface, electrode sensitivity for 5-HT can decline over the course of an experiment (Jackson et al., 1995). To monitor the sensitivity of the electrode to 5-HT, signal reproducibility was carefully monitored. In the event that an electrode clearly had become insensitive to 5-HT (i.e., for the same amount of 5-HT ejected, signal amplitude deteriorated by $>20 \%$ of original value), the electrode/micropipette assembly was removed, the electrode discarded, and a new electrode attached to the micropipette before recordings continued. This occurred in $<5 \%$ of experiments and with equivalent frequency across genotypes.

At the conclusion of the experiment, an electrolytic lesion was made to mark the placement of the electrode tip. The brain was removed, rapidly frozen on dry ice and stored at $-80^{\circ} \mathrm{C}$ until use. At this time brains were thawed to $-15^{\circ} \mathrm{C}$ and sliced into $20-\mu \mathrm{m}$-thick sections for histological verification of electrode localization (see Fig. $1 A$ ). Only data from mice in which the electrode was confirmed to be in the CA3 region of the hippocampus were included in data analyses. An insufficient number of placements falling outside this region prevented assessment of the effect of ethanol on 5-HT clearance in other hippocampal regions.

Effects of locally applied ethanol on 5-HT clearance. Exogenous 5-HT was applied into the $\mathrm{CA} 3$ region of the hippocampus by pressure ejection (5-25 psi for 0.25-3.0 s). Advantages of this approach are that clearance can be measured without an associated "release" component and that measurements can be made in vivo with excellent temporal (millisecond) resolution. The amount of 5-HT pressure ejected was adjusted so that baseline peak signal amplitudes did not exceed $1.5 \mu \mathrm{M}$. By keeping signal amplitudes in this range we can maintain the sensitivity of the electrode for 5-HT for several hours.

Once reproducible 5-HT electrochemical signals were obtained, ethanol was applied into the CA3 region of hippocampus 2 min before the next application of 5-HT. Different nanomole amounts of ethanol were delivered by varying the volume ejected. The nanomole amount was determined according to $\mathrm{M}=\mathrm{mol} / \mathrm{L}$, where $\mathrm{M}$ is the molar barrel concentration, $\mathrm{L}$ is the volume ejection (liters) and mol is the number of moles of ethanol delivered. This drug application protocol was chosen to cause minimal disturbance to the baseline electrochemical signal and to allow sufficient time for ethanol to diffuse to the recording site. Serotonin was applied again at 10,20, and $30 \mathrm{~min}$ after ethanol. This time interval ensured that each signal produced by 5 -HT had returned to baseline before the next ejection of 5-HT, ethanol, or vehicle. Two signal parameters were analyzed: the peak signal amplitude and the $T_{80}$ time-course parameter. $T_{80}$ is defined as the time for the signal to decline by $80 \%$ of the peak signal amplitude and is illustrated in Figure $1 C$.

The barrel concentration of ethanol (100 mM) was based on the literature and selected to approximate local concentrations that produce effects ranging from mild sedation to full anesthesia in rodents (Alexi and Azmitia, 1991). This barrel concentration of ethanol is estimated to yield concentrations at the recording site in the range of $0.5-10.0 \mathrm{~mm}$, a range that is wholly consistent with extracellular brain concentrations reported after systemic administration of $1 \mathrm{~g} / \mathrm{kg}$ of ethanol (Robinson et al., 2000). It is not possible to calculate the precise concentration of ethanol that reaches the recording site because this is dependent on diffusion through the extracellular matrix (Near et al., 1988; Nicholson, 1995; Rice and Nicholson, 1995; Nicholson and Syková, 1998). However, it has been 

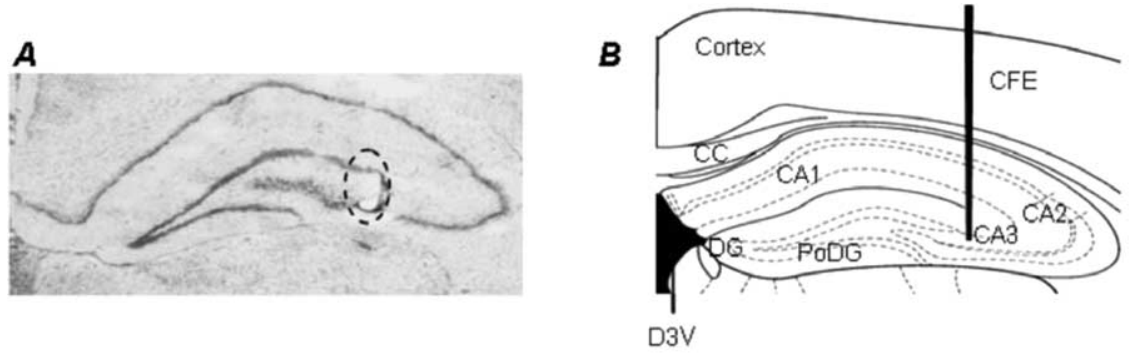

c
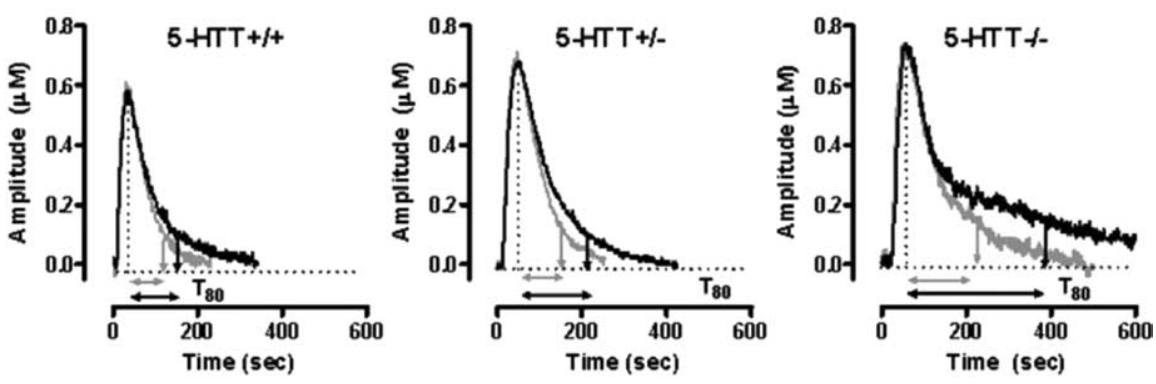

Figure 1. Electrode placement and signals produced by pressure ejection of 5-HT into the CA3 region of hippocampus. $\boldsymbol{A}_{\text {, }}$ Thionin-stained coronal section showing the mouse hippocampus at the level of plate 47 (Franklin and Paxinos, 1997). The circled area shows the electrolytic lesion made to mark the placement of the active recording area of the carbon fiber electrode in the $C A 3$ region of the hippocampus. Note the minimal tissue damage created by the electrode tract. $\boldsymbol{B}$, Plate 47 adapted from Franklin and Paxinos showing recording site within the CA3 region of mouse hippocampus. $C$, Representative oxidation currents (converted to micromolar values) produced by pressure ejection of 5-HT into the hippocampus before (gray line) and $2 \mathrm{~min}$ after ethanol (10 $\mathrm{nmol}$ ) treatment in $5-\mathrm{HTT}+/+,+/-$, and $-/-$ mice. Raw tracings are superimposed for ease of comparison. Note the marked increase in $T_{80}$ in 5-HTT - / - mice compared with 5-HTT + / + and 5-HTT + / - mice. CFE, Carbon fiber electrode; CC, corpus callosum; D3V, dorsal third ventricle; DG, dentate gyrus; PoDG, polymorph layer of dentate gyrus; $C A 1$, $C A 2$, and $C A 3$, regions of hippocampus.

estimated that there is at least a tenfold dilution in the concentration of drug pressure ejected from a micropipette at a distance of $300 \mu \mathrm{m}$ from the recording electrode (Gerhardt and Palmer, 1987). This seems a conservative estimate based on our own data, which show that when $25 \mathrm{~nL}$ of $200 \mu \mathrm{M} 5-\mathrm{HT}$ is pressure ejected $200 \mu \mathrm{m}$ away from the recording electrode a signal of $\sim 1 \mu \mathrm{M} 5-\mathrm{HT}$ is registered at the recording electrode. It is reasonable to suggest then that a 10 - to 200 -fold dilution in drug concentration occurs by the time it diffuses to the recording electrode. Thus, the barrel concentration of ethanol used here $(100 \mathrm{~mm})$, when pressure ejected into brain, would yield a pharmacologically and physiologically relevant concentration at the recording electrode $(\sim 0.5-10 \mathrm{~mm})$.

Effects of systemically administered ethanol on 5-HT clearance. The effects of systemically administered on 5-HT clearance in the CA3 region of hippocampus were measured using methods described above with the exception that ethanol $(2.5 \mathrm{~g} / \mathrm{kg})$ or an equivalent volume of $0.9 \%$ saline vehicle was injected intraperitoneally. Five minutes later, 5-HT was locally ejected into the hippocampus and at $10 \mathrm{~min}$ intervals for $35 \mathrm{~min}$. In these experiments, the barrels of the micropipette contained only 5-HT.

Effect of ethanol in combination with a selective serotonin reuptake inhibitor on 5-HT clearance. The effect of a combination of ethanol and the 5-HTT antagonist fluvoxamine on 5-HT clearance in the CA3 region of the hippocampus was assessed in 5 -HTT $+/+$ mice using methods described above. We chose fluvoxamine because we have used it extensively in our studies of serotonin clearance in mice (e.g., Montañez et al., 2003) and, as such, have already established dose-response curves for the ability of locally applied fluvoxamine to inhibit serotonin clearance in wild-type mice. For intrahippocampal delivery of drug, micropipette barrels were filled with either a solution containing 55 pmol fluvoxamine, a "dose" that produces maximal inhibition of 5-HT clearance in wild-type mice, and $20 \mathrm{nmol}$ ethanol, the highest dose used in the present study, or fluvoxamine, ethanol, or vehicle by themselves. For systemic drug delivery, mice were injected intraperitoneally $(2 \mathrm{ml} / \mathrm{kg}$ body weight $)$ with either a solution containing $5 \mathrm{mg} / \mathrm{ml}$ fluvoxamine and $1.25 \mathrm{~g} / \mathrm{ml}$ ethanol to deliver $10 \mathrm{mg} / \mathrm{kg}$ and $2.5 \mathrm{~g} / \mathrm{kg}$ of fluvoxamine and ethanol, respectively. Separate groups of mice received each drug by itself or PBS vehicle.

Ethanol-induced hypnosis/sedation. The hypnotic/sedative effects of ethanol were assessed by measuring sleep time, as described previously (Crabbe et al., 1981; Boyce-Rustay and Holmes, 2005). 5-HTT $+/+,+/-$, and $-/-$ mice were placed in the supine position in "V"shaped chambers immediately after intraperitoneal injection of 3.0 or $4.0 \mathrm{~g} / \mathrm{kg}$ of ethanol ( 200 proof prepared in $0.9 \%$ saline to produce $20 \% \mathrm{v} / \mathrm{v}$ solutions). The time between injection and recovery of the righting reflex (turning onto all four paws two times in $30 \mathrm{~s}$ after an instance of self-righting) was measured.

The effects of pretreatment with the 5-HTT antagonists citalopram and fluoxetine on the sedative/hypnotic effects of ethanol were measured in nonmutant $\mathrm{C} 57 \mathrm{BL} / 6 \mathrm{~J}$ mice and, in the case of fluoxetine, in 5 -HTT $+/+,+/-$, and $-/-$ mice. Citalopram hydrobromide $(0,10$, 20 , or $30 \mathrm{mg} / \mathrm{kg}$ ) or fluoxetine hydrochloride $(0,10,20$, or $30 \mathrm{mg} / \mathrm{kg})$ (both obtained from Sigma, St. Louis, MO) was dissolved in $0.9 \%$ saline and injected intraperitoneally at $10 \mathrm{ml} / \mathrm{kg}$ body weight $30 \mathrm{~min}$ before ethanol ( $3 \mathrm{~g} / \mathrm{kg})$ injection, and mice were tested as above. On recovery of righting reflex, trunk blood was taken via rapid decapitation for blood ethanol concentrations using the Analox AM1 alcohol analyzer (Analox Instruments, Lunenburg, MA).

Statistical analysis. The effects of genotype on ethanol clearance and sedation/hypnosis were analyzed using ANOVA followed by Bonferroni's and Student-Newman-Keuls post hoc tests. All data are presented as mean and SEM.

\section{Results}

Basal 5-HT clearance is slower in 5-HTT $-/-$ mice

As anticipated from our previous findings (Montañez et al., 2003 ) there was a significant effect of genotype on baseline 5-HT clearance in the experiment examining the effects of locally applied ethanol on 5-HT clearance. Here $T_{80}$ values for 5-HT clearance before application of ethanol were significantly higher in 5 -HTT $-/-(113 \pm 15 \mathrm{~s})$ but not 5 -HTT $+/-(75 \pm 5 \mathrm{~s})$ mice compared with 5 -HTT $+/+$ controls $(61 \pm 9 \mathrm{~s}$ ) (main effect of genotype: $\left.F_{(2,28)}=6.94 ; p<0.01\right)$. Peak signal amplitudes did not differ between genotypes (5-HTT-/-, $0.75 \pm 0.06 \mu \mathrm{M}$; 5 -HTT $+/-, 0.71 \pm 0.06 \mu \mathrm{M} ; 5$-HTT $+/+, 0.76 \pm 0.06 \mu \mathrm{M})$. The genotype-dependent differences are illustrated in Figure $1 C$, which shows the oxidation current, converted to a micromolar concentration, produced by pressure ejection of 5-HT ( $5 \mathrm{pmol})$ into the CA3 region of the hippocampus of 5 -HTT $+/+,+/-$, and $-/-$ mice. Note the markedly longer time course for $5-\mathrm{HT}$ clearance in 5 -HTT $-/-$ mice compared with $5-\mathrm{HTT}+/+$ or 5 -HTT $+/-$ mice (baseline clearance denoted by gray line in each panel). In these examples, the baseline $T_{80}$ values were 77,83 , and $179 \mathrm{~s}$ for 5 -HTT $+/+,+/-$, and $-/-$ mice respectively.

Retarded basal 5-HT clearance in 5-HTT-/- mice was replicated in the experiment examining the effects of systemically administered ethanol on 5-HT clearance. As shown in Figure $3 A-C, T_{80}$ values in mice before ethanol injection were significantly greater in 5 -HTT $-/-$ mice than in 5 -HTT $+/-$ or 5 -HTT $+/+$ mice (main effect of genotype: $F_{(2,28)}=4.32 ; p<$ $0.05)$. Again, peak signal amplitudes did not differ between geno- 

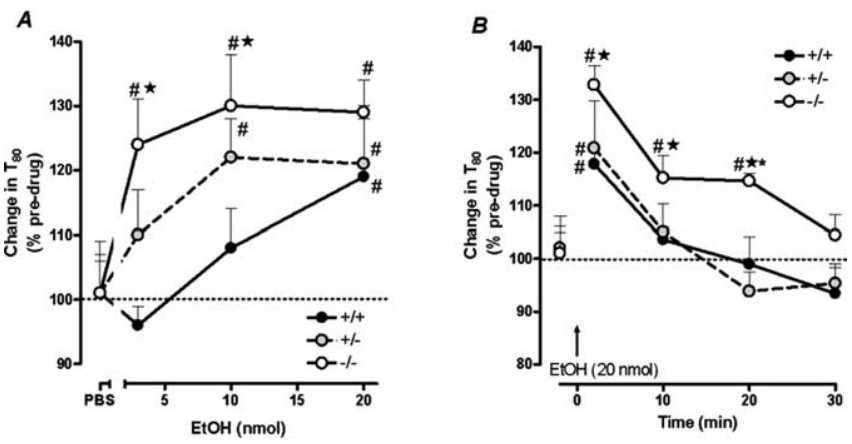

Figure 2. 5-HT clearance-inhibiting effects of hippocampally applied ethanol are potentiated in 5-HTT mutant mice. $\boldsymbol{A}$, Increasing concentrations of hippocampally applied ethanol caused a significant percent increase in $T_{80}$ values over pre-ethanol baseline in hippocampus of all genotypes, but to a greater extent in $5-\mathrm{HTT}-/-$ and $5-\mathrm{HTT}+/-$ mice than $5-\mathrm{HTT}+/+$ controls. Data shown are for 2 min after ethanol administration ( $n=7-14 /$ genotype/treatment). $\boldsymbol{B}, 5-\mathrm{HTT}-/-$ mice showed a significantly greater and more prolonged percentage increase in $T_{80}$ values in hippocampus than $5-\mathrm{HTT}+/-$ mice or 5 -HTT $+/+$ controls over the course of the recording session. Data shown are for $20 \mathrm{nmol}$ ethanol ( $n=5-6 /$ genotype). Summary data in Figures $2-5$ are means \pm SEM. ${ }^{\#} p<0.05$ versus pre-ethanol baseline; ${ }^{\star} p<$ 0.05 versus $5-\mathrm{HTT}+/+;{ }^{*} p<0.05$ versus $5-\mathrm{HTT}+/-$ at the same ethanol concentration.

types (5-HTT-/-, $0.70 \pm 0.07 \mu \mathrm{M} ; 5-\mathrm{HTT}+/-, 0.82 \pm 0.06 \mu \mathrm{M}$; $5-\mathrm{HTT}+/+, 0.80 \pm 0.06 \mu \mathrm{M})$.

\section{Local application of ethanol inhibits 5-HT clearance in a 5-HTT-genotype-dependent manner}

Local application of ethanol into the hippocampus significantly reduced the rate of 5-HT clearance in this region in a genotypedependent manner. 5-HT was pressure ejected into the CA3 region to generate reproducible signals and ethanol $(3,10$, or 20 nmol) or an equivalent volume of PBS vehicle was applied directly into this region. Ethanol slowed 5-HT clearance in a concentration-dependent manner $\left(F_{(3,79)}=5.07 ; p<0.01\right)$ that was further affected by 5 -HTT genotype $\left(F_{(2,79)}=3.55 ; p<0.05\right)$. Representative tracings illustrating this effect are shown in Figure $1 C$, which highlights the genotype-dependent difference in clearance of exogenously applied 5-HT after administration of 10 nmol ethanol. Two minutes after ethanol administration, only a modest, nonsignificant increase in $T_{80}$ occurred in $5-\mathrm{HTT}+/+$ mice, whereas inhibition of 5 -HT clearance was more pronounced in 5 -HTT $+/-$ and even further exaggerated in 5 -HTT $-/-$ mice. Figure $2 A$ provides summary data for both the genotype and concentration-dependency of the effect of ethanol to inhibit 5-HT clearance $2 \mathrm{~min}$ after its application. In 5 -HTT $+/+$ mice, ethanol significantly increased $T_{80}$ values from pre-ethanol baseline only at the highest concentration of ethanol (20 nmol). By comparison, ethanol concentrations of both 10 and $20 \mathrm{nmol}$ caused a significant percent increase in $T_{80}$ values in 5 -HTT $+/-$ mice. In 5-HTT $-/-$ mice, percent increases in $T_{80}$ values over baseline were seen at all ethanol concentrations. PBS treatment did not affect 5-HT clearance in any genotype. Peak 5-HT signal amplitude was not affected by ethanol.

The potentiation of ethanol inhibition of 5-HT clearance in 5 -HTT $-/-$ mice is further highlighted by the duration of the effect of ethanol. Although the magnitude of inhibition was similar among genotypes after application of $20 \mathrm{nmol}$ ethanol, 5 -HTT $-/-$ mice showed a significantly greater percent increase in $T_{80}$ values than $5-\mathrm{HTT}+/-$ mice or $5-\mathrm{HTT}+/+$ controls over the course of the recording session $\left(F_{(2,39)}=5.82 ; p<0.05\right)$ (Fig. $2 B)$. Whereas 5 -HT clearance rates returned to predrug baselines by $10 \mathrm{~min}$, the change in $T_{80}$ values remained significantly elevated above baseline until $30 \mathrm{~min}$ in 5 -HTT $-/-$ mice.

\section{Systemically administered ethanol inhibits 5-HT clearance in} a 5-HTT-genotype-dependent manner

We next studied whether systemically administered ethanol could also inhibit 5-HT-clearance in the hippocampus. This route of ethanol treatment significantly reduced the rate of 5-HT clearance in a genotype-dependent manner. In 5-HTT $+/+$ mice, ethanol caused a significant increase in $T_{80}$ values $5 \mathrm{~min}$ after ethanol treatment but not at later time points (main effect of time: $F_{(4,39)}=3.57 ; p<0.05$ ) (Fig. $3 A$ ). Inhibition of 5-HT clearance by ethanol was again potentiated in 5 -HTT $+/-$ mice. Ethanol increased $T_{80}$ values in $5-\mathrm{HTT}+/-$ mice at 5 and $15 \mathrm{~min}$ before returning to baseline values by $25 \mathrm{~min}$ after treatment (main effect of time: $F_{(4,39)}=3.78 ; p<0.05$ ) (Fig. 3B). This effect was even more pronounced in 5 -HTT $-/-$ mice, with $T_{80}$ values elevated at all time points studied (main effect of time: $F_{(4,44)}=$ $3.89 ; p<0.05$ ) (Fig. 3C). Saline injection did not affect the time course for 5-HT clearance in any genotype.

The greater capacity for systemic ethanol to inhibit 5-HT clearance in 5 -HTT $-/-$ mice was further demonstrated by comparing the percent increase in $T_{80}$ values induced by ethanol treatment. In 5 -HTT $-/-$ and $5-\mathrm{HTT}+/-$ mice, ethanol produced a significantly greater percent increase in $T_{80}$ values across the recording session than in $5-\mathrm{HTT}+/+$ mice (main effect of genotype: $\left.F_{(2,88)}=3.44 ; p<0.05\right)$ (Fig. $3 D$ ). Figure $3 E$ illustrates the oxidation current, converted to a micromolar concentration using a calibration factor determined in vitro, produced by pressure ejection of 5-HT into the CA3 region of hippocampus of a 5 -HTT $-/-$ mouse before and 5 min after ethanol ( $2.5 \mathrm{~g} / \mathrm{kg}$, i.p.). Note the marked increase in the time course for clearance of 5 -HT as well as a small increase in amplitude of the signal produced by local pressure ejection of 5-HT after ethanol administration relative to the signal obtained before ethanol.

\section{Local or systemic coapplication of ethanol and a 5-HTT antagonist inhibits 5-HT clearance to a greater extent than either treatment alone}

We next assessed whether the potentiation of ethanol-induced inhibition of 5 -HT clearance seen in 5 -HTT $-/-$ mice could be mimicked by cotreatment with the 5-HTT antagonist fluvoxamine in 5 -HTT $+/+$ mice. Figure 4 depicts the effect of either locally $(A)$ or systemically $(B)$ administered fluvoxamine, ethanol, or a combination of the two, on 5-HT clearance in hippocampus. Locally applied fluvoxamine $(55 \mathrm{pmol})$ alone inhibited the time course for 5-HT clearance by $\sim 30 \%$. Replicating our present data (Fig. 2), locally applied ethanol $(20 \mathrm{nmol})$ alone caused modest inhibition of serotonin clearance $(\sim 20 \%)$. By comparison, coadministration of ethanol and fluvoxamine inhibited 5-HT clearance by $\sim 70 \%$ (Fig. $4 A$ ) (main effect treatment: $F_{(3,15)}=3.80$; $p<0.05)$.

After systemic treatment, either fluvoxamine or ethanol given alone each inhibited the time course for 5-HT clearance by $\sim 20 \%$. Combined systemic application of fluvoxamine (10 mg/ $\mathrm{kg})$ and ethanol $(2.5 \mathrm{~g} / \mathrm{kg})$ also produced a significantly greater inhibition $(\sim 70 \%)$ of 5 -HT clearance (Fig. $4 B$ ) (main effect treatment: $F_{(3,17)}=6.23$; $\left.p<0.01\right)$.

Whereas none of the single or combined treatments significantly altered signal amplitude, regardless of route of administration, the systemic fluvoxamine-ethanol treatment combination produced a trend for increased signal amplitude (pretreatment, $0.56 \pm 0.04 \mu \mathrm{M}$ vs post-treatment, $0.64 \pm 0.05 \mu \mathrm{M} ; p<0.08$, 

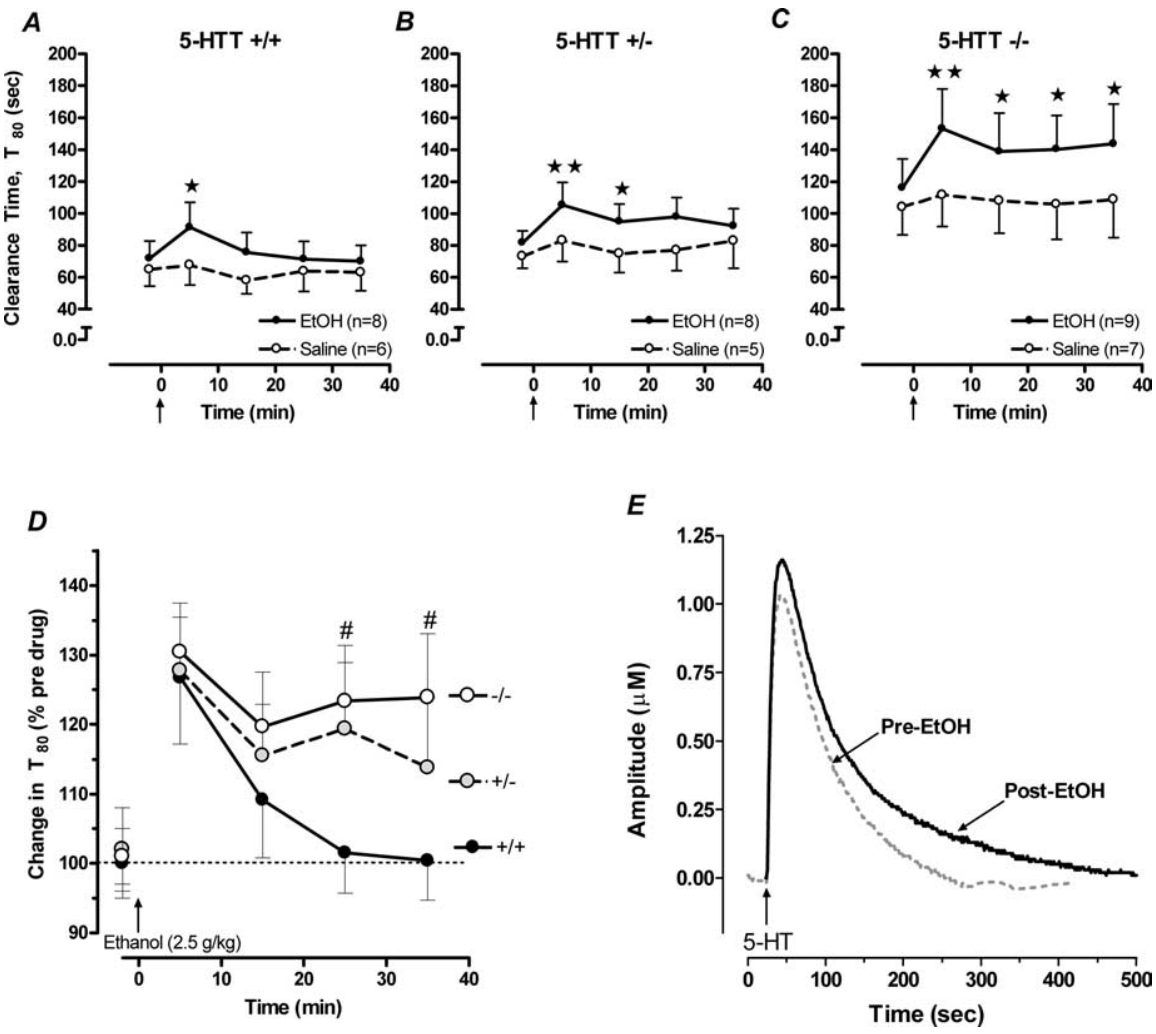

Figure 3. 5-HT clearance-inhibiting effects of systemically administered ethanol are potentiated in 5-HTT mutant mice. $\boldsymbol{A}$, Systemic administration of ethanol (denoted by arrow on lower abscissa) caused a significant, transient increase in $T_{80}$ values in the hippocampus of $5-\mathrm{HTT}+/+$ mice. This effect was accentuated in $5-\mathrm{HTT}+/-$ mice $(\boldsymbol{B})$ and markedly potentiated in 5 -HTT - / - mice ( $C$ ) ( $n=5-9 /$ genotype/treatment). $\boldsymbol{D}$, The significantly retarded rate of 5 -HT clearance in 5 -HTT $-/-$ and 5 - $\mathrm{HTT}+/$ - mice is further illustrated by the prolonged percentage increase in $T_{80}$ basal values after ethanol treatment in these mice relative to 5 - $\mathrm{HTT}+/+$ controls. $\boldsymbol{E}$, Representative oxidation currents (converted to micromolar values) produced by pressure ejection of 5-HT into the hippocampus before (gray line) and 5 min after ethanol treatment in $5-\mathrm{HTT}-1-$ mice. ${ }^{\star} p<0.05$ ${ }^{\star \star} p<0.01$ versus time point $0 ;{ }^{\#} p<0.05$ versus same time point in $5-\mathrm{HTT}+/+$.

A

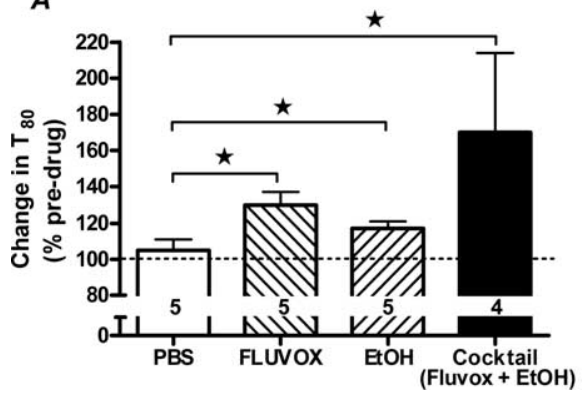

B

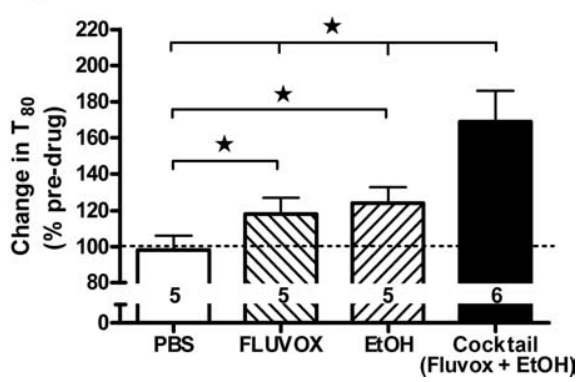

Figure 4. 5-HT clearance-inhibiting effects of either locally or systemically administered ethanol are potentiated by cotreatment with a 5 -HTT antagonist in 5-HTT + / + mice. $A$, Local coadministration of ethanol and fluvoxamine produced a significantly greater increase in $T_{80}$ values in the hippocampus than either treatment alone ( $n=4-5 /$ treatment). $\boldsymbol{B}$, Systemic coadministration of ethanol and fluvoxamine produced a significantly greater increase in $T_{80}$ values in the hippocampus than either treatment alone ( $n=5-6 /$ treatment). ${ }^{\star} p<0.05$.

paired $t$ test). Vehicle was without effect on any signal parameter regardless of route of administration.

\section{Sedative/hypnotic effects of ethanol are potentiated in 5-HTT $-/-$ mice and by a 5-HTT antagonist}

Given the profound alterations in the 5-HT clearance-inhibiting effects of ethanol in 5-HTT-/- mice, we next assessed whether behavioral responses to ethanol were also altered in these mice. The sedative/hypnotic effects of ethanol were significantly poten-

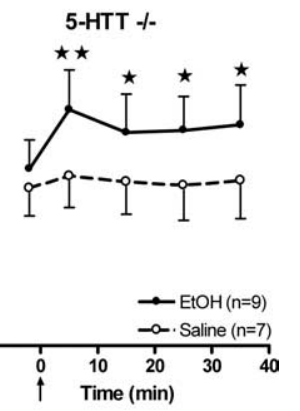

tiated in 5 -HTT $-/-$ mice. As shown in Figure 5A, 5-HTT-/- mice showed significantly longer sleep-time duration than 5 -HTT $+/+$ controls after systemic administration of either 3 or $4 \mathrm{~g} / \mathrm{kg}$ of ethanol (main effect of genotype: $F_{(2,82)}=$ 9.90; $p<0.01)$. Blood ethanol concentrations at the time of recovery in 5-HTT-/- mice were significantly lower than in 5-HTT $+/+$ controls, indicating that increased sleep time was not simply caused by slower metabolism (main effect of genotype: $\left.F_{(2,23)}=4.38 ; p<0.05\right)$ (Table 1).

In nonmutant $\mathrm{C} 57 \mathrm{BL} / 6 \mathrm{~J}$ mice, pretreatment with fluoxetine but not citalopram also potentiated the sedative/hypnotic effects of ethanol. As shown in Figure 5, $B$ and $C$, sleep-time duration after systemic administration of $3 \mathrm{~g} / \mathrm{kg}$ of ethanol was significantly prolonged in mice pretreated with fluoxetine (main effect of dose: $\left.F_{(3,60)}=8.81 ; p<0.01\right)$ but not citalopram (main effect dose: not significant). Post hoc analysis revealed significantly longer sleep time after pretreatment with the highest dose $(30 \mathrm{mg} / \mathrm{kg})$ of fluoxetine only. Fluoxetine did not affect ethanol metabolism: blood ethanol concentrations at the time of recovery were significantly lower in mice treated with 30 $\mathrm{mg} / \mathrm{kg}$ of fluoxetine than vehicle-treated controls (main effect of dose: $F_{(3,16)}=$ 2.08, $p=0.07$; post hoc comparison, $p<$ 0.05) (Table 1).

The sleep-time-potentiating effect of high-dose fluoxetine was maintained in 5-HTT - / - mice. As shown in Figure 5D, sleep-time duration after systemic administration of $3 \mathrm{~g} / \mathrm{kg}$ of ethanol was significantly prolonged by pretreatment with fluoxetine to a similar extent in 5 -HTT $+/+,+/-$, and $-/-$ mice (main effect of fluoxetine treatment: $F_{(1,55)}=$ 50.09; $p<0.01)$. 5-HTT $-/-$ generally showed longer sleep-time durations (main effect of genotype: $F_{(2,55)}=7.00$; $p<0.01)$.

\section{Discussion}

\section{Ethanol inhibits clearance of 5-HT} in vivo

Previous studies in rodents have shown that ethanol elevates extracellular levels of forebrain 5-HT (McBride et al., 1993; Virkkunen and Linnoila, 1997). Present findings demonstrate that local application of ethanol in the CA3 region of the hippocampus caused a significant and concentration-dependent inhibition of 5-HT clearance in that region. Similar effects on hippocampal 5-HT clearance were produced by systemic injection of ethanol at a behaviorally relevant dose $(2.5 \mathrm{~g} / \mathrm{kg})$. The magnitude of ethanol-induced inhibition was comparable with that produced by treatment with a 5-HTT antagonist under similar ex- 

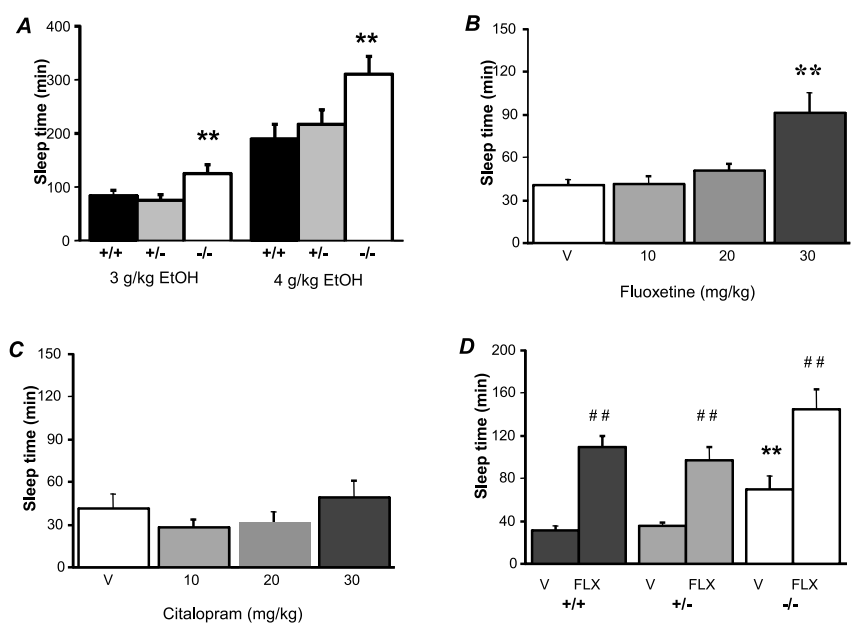

Figure 5. Sedative/hypnotic effects of ethanol are potentiated in 5-HTT-/ - mice. $\boldsymbol{A}$, 5 -HTT $-/-$ mice showed significantly longer sleep-time duration than $5-\mathrm{HTT}+/+$ controls after systemic administration of either 3 or $4 \mathrm{~g} / \mathrm{kg}$ of ethanol ( $n=5-23 /$ genotype/dose). $\boldsymbol{B}$, Sleep time duration after systemic administration of $3 \mathrm{~g} / \mathrm{kg}$ of ethanol was significantly prolonged in nonmutant $\mathrm{C} 57 \mathrm{BL} / 6 \mathrm{~J}$ mice pretreated with $30 \mathrm{mg} / \mathrm{kg}$ of fluoxetine than in vehiclepretreated (V) controls ( $n=14-17 /$ dose). C, Sleep time duration after systemic administration of $3 \mathrm{~g} / \mathrm{kg}$ of ethanol in nonmutant $\mathrm{C} 57 \mathrm{BL} / 6 \mathrm{~J}$ was not significantly affected by pretreatment with citalopram at any dose tested ( $n=8-12 /$ dose). $D$, Sleep-time duration after systemic administration of $3 \mathrm{~g} / \mathrm{kg}$ of ethanol was significantly prolonged by pretreatment with $30 \mathrm{mg} / \mathrm{kg}$ of fluoxetine to a similar extent in $5-\mathrm{HTT}+/+, 5-\mathrm{HTT}+/-$, and $5-\mathrm{HTT}-/-$ mice $(n=7-12 /$ dose). ${ }^{* *} p<0.01$ versus $+/+;{ }^{\# \#} p<0.01$ versus $V$.

Table 1. Blood ethanol concentrations at recovery of the righting reflex

\begin{tabular}{lc}
\hline Effects of 5-HTT genotype & \\
\hline $\begin{array}{ll}\text { Genotype } \\
+/+\end{array}$ & $352 \pm 9$ \\
$+1-$ & $329 \pm 9$ \\
$-1-$ & $* 302 \pm 14$
\end{tabular}

Effects of pretreatment with citalopram and fluoxetine

\begin{tabular}{clc}
\hline Dose $(\mathrm{mg} / \mathrm{kg})$ & Citalopram & Fluoxetine \\
\hline vehicle & $344 \pm 9$ & $338 \pm 13$ \\
10 & $372 \pm 13$ & $339 \pm 10$ \\
20 & $352 \pm 8$ & $342 \pm 5$ \\
30 & $340 \pm 8$ & $* 296 \pm 20$
\end{tabular}

Increased sensitivity to the sedative/hypnotic effects of ethanol in 5-HTT-/ - mice was not caused by abnormal ethanol metabolism. Blood ethanol concentrations $(\mathrm{mg} / \mathrm{dl})$ at recovery of the loss of righting reflex were significantly lower in longer-sleeping 5-HTT $-/-$ mice than $5-\mathrm{HTT}+/+$ controls ( $n=7-10$ per genotype). Increased sensitivity to the sedative/hypnotic effects of ethanol after high-dose fluoxetine pretreatment in nonmutant C57BL/6J mice was not caused by abnormal ethanol metabolism. Blood ethanol concentrations $(\mathrm{mg} / \mathrm{dl})$ at the recovery of the loss of righting reflex were significantly lower in longer-sleeping mice receiving $30 \mathrm{mg} / \mathrm{kg}$ fluoxetine pretreatment than vehicle-treated controls ( $n=5$ per dose). Citalopram pretreatment did not affect sleep time or blood ethanol concentrations ( $n=8-12$ per dose). Data are mean $\pm S E M ;{ }^{*} p<0.05$ versus $+/+$ or vehicle.

perimental conditions (Montañez et al., 2003) (present data). Together these data provide the first direct in vivo evidence that this effect of ethanol may occur via inhibition of 5-HT clearance from extracellular space.

It is unlikely that the clearance-inhibiting effect of ethanol was an artifact of ethanol-induced release of 5-HT into the extracellular pool because locally applied ethanol did not evoke an electrochemical signal (i.e., evoke measurable neurotransmitter release). Activity-dependent release of 5-HT by ethanol is further ruled out by the observation that ethanol typically inhibits, rather than excites, cell firing of 5-HT-producing raphe nuclei innervating the hippocampus (Chu, 1984; Pistis et al., 1997; Thielen et al., 2001). An alternative explanation is that clearance inhibition was a consequence of a nonspecific effect of ethanol, such as fluidiza- tion of the cell membrane (Alexi and Azmitia, 1991), rather than blockade of 5-HT reuptake. However, such a nonspecific effect could not readily account for the finding that 5-HT clearance inhibition effects of ethanol were strongly 5-HTT-genotypedependent (see below), although the possibility that lipid-protein or lipid-lipid interactions controlling neural membrane function might differ among 5-HTT genotypes cannot be fully discounted at this point.

\section{5-HTT inactivation potentiates the 5-HT clearance-inhibiting effect of ethanol}

Reuptake of 5-HT by the 5-HTT is the principle active means by which 5-HT is cleared from extracellular space in the brain (Fuller and Wong, 1990; Blakely et al., 1998). On this basis, we hypothesized that antagonism of the 5-HTT might be the mechanism mediating the clearance-inhibiting effects of ethanol and, ergo, that loss of 5-HTT function in mutant mice lacking the 5-HTT would abolish ethanol-induced inhibition of 5-HT clearance. Results showed the opposite. The ability of hippocampally applied ethanol to inhibit 5-HT clearance was significantly greater in 5-HTT $-/-$ and 5 -HTT $+/-$ mice than in $5-\mathrm{HTT}+/+$ controls. This genotypic effect was especially apparent in the marked shift to the left in the concentration-effect curve for ethanol to inhibit 5-HT clearance in mutants relative to 5 -HTT $+/+$ controls, but was also evident in the time course for recovery of 5-HT clearance to baseline levels. The ability of systemically administered ethanol to inhibit hippocampal 5-HT clearance was also potentiated in 5-HTT mutant mice. Again, a genotype-dependent effect was manifest as a temporal prolongation of ethanol's inhibition of 5-HT clearance.

Together, these data demonstrate that the ability of ethanol to inhibit 5-HT clearance is not mediated via an antagonist action at the principle site of 5-HT clearance, the 5-HTT. This was further confirmed by the finding that pharmacological inactivation of the 5-HTT in 5-HTT $+/+$ mice also potentiated ethanol inhibition of 5-HT clearance. Cotreatment with ethanol and the 5-HTT antagonist fluvoxamine inhibited 5-HT clearance to a significantly greater extent than either treatment alone. This interaction was demonstrable when both drugs were given either locally or systemically. Thus, the mechanism by which ethanol inhibits 5-HT clearance appears to be functionally unmasked by inactivation of the 5-HTT. According to this model, ethanol would produce modest and transient increases in extracellular 5-HT under conditions in which 5-HTT-mediated 5-HT reuptake would adequately compensate for the clearance-inhibiting effects of ethanol at some secondary site of action. However, the effects of ethanol on extracellular 5-HT would be significantly amplified by a loss of 5-HTT function resulting from genetic variation, pharmacologic antagonism, or any other factor causing functional downregulation of 5-HTT, such as stress (McKittrick et al., 2000; Bethea et al., 2005) and even chronic exposure to ethanol itself (Heinz et al., 2000, 2004).

A major unanswered question arising from these data is the identity of the site by which ethanol can inhibit removal of 5-HT from the extracellular space. Previous studies have shown that 5-HT can be taken up by transporters other than the 5-HTT, including the dopamine transporter (DAT) (Callaghan et al., 2005; Zhou et al., 2005) and norepinephrine transporter (NET) (Daws et al., 2005), and that DAT-mediated clearance of 5-HT is upregulated in the 5-HTT-/- mice (Zhou et al., 2002). There is also evidence that ethanol can inhibit dopamine (Robinson et al., 2005) and norepinephrine (Lin et al., 1993, 1997) uptake via effects on DAT and NET respectively. However, given the sparse 
expression of DAT in hippocampus (Javitch et al., 1985), it is unlikely that an ethanol action at DAT can explain the present findings. NET is expressed in the hippocampus and to a similar extent between 5 -HTT mutants, as evidenced by $\left[{ }^{3} \mathrm{H}\right]$ nisoxetine binding (Montañez et al., 2003). Thus, NET represents a reasonable candidate mechanism for the 5-HT-clearance-inhibiting effects of ethanol. However, ethanol actions in the brain are enormously complex with marked effects on the major inhibitory (GABA) and excitatory (glutamate) neurotransmitter systems as well as the monoamines (Chandler 2003; Heinz et al., 2004; Siggins et al., 2005), and it would be premature to explain the present data solely to an action on a single protein such as NET.

These data may help to explain inconsistencies in the literature regarding in vitro studies measuring the effect of ethanol on $\left[{ }^{3} \mathrm{H}\right]-5-\mathrm{HT}$ uptake into synaptosomes or platelets. In these studies, ethanol has been reported to increase, decrease, or produce no change in $\left[{ }^{3} \mathrm{H}\right]-5-\mathrm{HT}$ uptake (Roach et al., 1973; Daoust et al., 1991a,b; LeMarquand et al., 1994; Javors et al., 2000). Although a variety of methodological variables may have contributed to this inconsistency, one important factor could be variation between assays in the function of the 5-HTT and/or the site of ethanol's effect on reuptake.

\section{5-HTT inactivation potentiates behavioral effects of ethanol}

Genetic and pharmacological inactivation of the 5-HTT affected behavioral as well as neural effects of ethanol. 5-HTT-/- mice showed increased sensitivity to the sedative/hypnotic effects of ethanol as compared with 5-HTT $+/+$ controls. In addition, and providing another parallel with the neural data discussed above, cotreatment with ethanol and the 5-HTT antagonist fluoxetine also potentiated these behavioral actions of ethanol in nonmutant C57BL/6J mice. Neither of these effects could be explained by retarded ethanol metabolism as demonstrated by analysis of blood ethanol concentrations at recovery. Interestingly, however, fluoxetine only increased ethanol-induced sedation/hypnosis at relatively high doses $(30 \mathrm{mg} / \mathrm{kg})$ that are nonselective for the 5-HTT. The 5-HTT-independent nature of this effect of highdose fluoxetine was confirmed by the observation that it was extant in 5-HTT $-/-$ mice. Moreover, cotreatment of nonmutant C57BL/6J with the highly selective 5-HTT antagonist citalopram did not affect ethanol-induced sedation/hypnosis at doses up to $30 \mathrm{mg} / \mathrm{kg}$. Thus, whereas it appears that genetically driven loss of 5-HTT is sufficient to alter these behavioral effects of ethanol, selective pharmacological inactivation of 5-HTT is not.

This pattern of behavioral effects differs from the ability of either form of 5-HTT manipulation to potentiate the effects of ethanol on hippocampal 5-HT clearance. However, this apparent disconnect is perhaps not unexpected given that extracellular 5 -HT in the hippocampus provides a focal snapshot of the effects of ethanol, although ethanol-induced sedation/hypnosis is likely to result from more widespread changes in brain 5-HT and interacting systems. Indeed, the observation that only nonselective doses of fluoxetine potentiated the behavioral effects of ethanol may be a further reflection of this. For example, and pertinent to the earlier discussion of interactions between ethanol and NET, high doses of fluoxetine antagonize NET (Frazer, 1997). Also of interest in this context, recent studies have shown that NET-null mutation and treatment with NET antagonists significantly potentiates the sedative/hypnotic effects of ethanol (Weinshenker et al., 2000; Haughey et al., 2005). Therefore, although loss of 5-HTT may be sufficient to amplify the effects of ethanol on extracellular 5-HT in hippocampus, inactivation of both 5-HTT and possibly NET may be necessary to manifest significant changes in the effects of ethanol on behavior.

This hypothesis remains to be critically evaluated by additional studies. Of note, it will be important to investigate (1) whether neural and behavioral effects of ethanol are altered by 5-HTT manipulations across a broader range of ethanol doses than presently tested, (2) whether alterations in 5-HT clearance after local and systemic ethanol application are seen in regions other than the hippocampus, and (3) whether other behavioral effects of ethanol are altered by genetic and/or pharmacological inactivation of 5-HTT.

Together with present findings, the results of these studies could have implications for understanding the effects of ethanol in man. As noted in the Introduction, there is a compelling literature implicating the 5-HTT in the pathophysiology and treatment of various neuropsychiatric diseases including alcoholism and mood disorders (Lesch et al., 1996; Caspi et al., 2003; Feinn et al., 2005; Hariri and Holmes 2006). Present findings add an important new dimension to this literature by providing novel insight into the biological basis of the effects of ethanol on brain 5-HT clearance and behavior.

\section{References}

Alexi T, Azmitia EC (1991) Ethanol stimulates [ $\left.{ }^{3} \mathrm{H}\right] 5-\mathrm{HT}$ high-affinity uptake by rat forebrain synaptosomes: role of 5-HT receptors and voltage channel blockers. Brain Res 544:243-247.

Bare DJ, McKinzie JH, McBride WJ (1998) Development of rapid tolerance to ethanol-stimulated serotonin release in the ventral hippocampus. Alcohol Clin Exp Res 22:1272-1276.

Barr CS, Newman TK, Schwandt M, Shannon C, Dvoskin RL, Lindell SG, Taubman J, Thompson B, Champoux M, Lesch KP, Goldman D, Suomi SJ, Higley JD (2004a) Sexual dichotomy of an interaction between early adversity and the serotonin transporter gene promoter variant in rhesus macaques. Proc Natl Acad Sci USA 101:12358-12363.

Barr CS, Newman TK, Lindell S, Shannon C, Champoux M, Lesch KP, Suomi SJ, Goldman D, Higley JD (2004b) Interaction between serotonin transporter gene variation and rearing condition in alcohol preference and consumption in female primates. Arch Gen Psychiatry 61:1146-1152.

Bengel D, Murphy DL, Andrews AM, Wichems CH, Feltner D, Heils A, Mossner R, Westphal H, Lesch KP (1998) Altered brain serotonin (5-HT) homeostasis and locomotor insensitivity to MDMA ("ecstasy") in 5-HT transporter deficient mice. Mol Pharmacol 53:649-655.

Bethea CL, Streicher JM, Mirkes SJ, Sanchez RL, Reddy AP, Cameron JL (2005) Serotonin-related gene expression in female monkeys with individual sensitivity to stress. Neuroscience 132:151-166.

Blakely RD, Ramamoorthy S, Schroeter S, Qian Y, Apparsundaram S, Galli A, DeFelice LJ (1998) Regulated phosphorylation and trafficking of antidepressant-sensitive serotonin transporter proteins. Biol Psychiatry 44:169-178.

Boyce-Rustay JM, Holmes A (2005) Functional roles of NMDA receptor NR2A and NR2B subunits in the acute intoxicating effects of ethanol in mice. Synapse 56:222-225.

Callaghan PD, Irvine RJ, Daws LC (2005) Differences in the in vivo dynamics of neurotransmitter release and serotonin uptake after acute paramethoxyamphetamine and 3,4-methylenedioxymethamphetamine revealed by chronoamperometry. Neurochem Int 7:350-361.

Caspi A, Sugden K, Moffitt TE, Taylor A, Craig IW, Harrington H, McClay J, Mill J, Martin J, Braithwaite A, Poulton R (2003) Influence of early life stress on depression: moderation by a polymorphism in the 5-HTT gene. Science 301:386-389.

Chandler LJ (2003) Ethanol and brain plasticity: receptors and molecular networks of the postsynaptic density as targets of ethanol. Pharmacol Ther 99:311-326.

Chu NS (1984) Response of midbrain raphe neurons to ethanol. Brain Res 311:348-352.

Crabbe JC, Gray DK, Young ER, Janowsky JS, Rigter H (1981) Initial sensitivity and tolerance to ethanol in mice: correlations among open field activity, hypothermia, and loss of righting reflex. Behav Neural Biol 33:188-203. 
Daoust M, Chretien P, Moore N, Saligaut C, Lhuintre JP, Boismare F (1985) Isolation and striatal $\left[{ }^{3} \mathrm{H}\right]$ serotonin uptake: Role in the voluntary intake of ethanol by rats. Pharmacol Biochem Behav 22:205-208.

Daoust M, Compagnon P, Legrand E, Boucly P (1991a) Ethanol intake and $\left[{ }^{3} \mathrm{H}\right]$ serotonin uptake I: a study in Fawn-Hooded rats. Life Sci 48:1969-1976.

Daoust M, Lhuintre JP, Ernouf D, Legrand E, Breton P, Boucly P (1991b) Ethanol intake and $\left[{ }^{3} \mathrm{H}\right]$ serotonin uptake II: a study in alcoholic patients using platelet $\left[{ }^{3} \mathrm{H}\right]$ paroxetine binding. Life Sci 48:1977-1983.

Daws LC, Toney GM, Davis DJ, Gerhardt GA, Frazer A (1997) In vivo chronoamperometric measurements of the clearance of exogenously applied serotonin in the rat dentate gyrus. J Neurosci Methods 78:139-150.

Daws LC, Irvine RJ, Callaghan PD, Toop NP, White JM, Bochner F (2000) Differential behavioural and neurochemical effects of paramethoxyamphetamine and 3,4-methylenedioxymethamphetamine in the rat. Prog Neuropsychopharmacol Biol Psychiatry 24:955-977.

Daws LC, Montañez S, Owens WA, Gould GG, Frazer A, Toney GM, Gerhardt GA (2005) Transport mechanisms governing serotonin clearance in vivo revealed by high-speed chronoamperometry. J Neurosci Methods 143:49-62.

Feinn R, Nellissery M, Kranzler HR (2005) Meta-analysis of the association of a functional serotonin transporter promoter polymorphism with alcohol dependence. Am J Med Genet Neuropsychiatr Genet 133:79-84.

Franklin KBJ, Paxinos G (1997) The mouse brain in stereotaxic coordinates. Sydney: Academic.

Frazer A (1997) Pharmacology of antidepressants. J Clin Psychopharmacol $17: 2 \mathrm{~S}-18 \mathrm{~S}$.

Fuller RW, Wong DT (1990) Serotonin uptake and serotonin uptake inhibition. Ann NY Acad Sci 600:68-78.

Gerhardt GA, Palmer MR (1987) Characterization of the techniques of pressure ejection and microiontophoresis using in vivo electrochemistry. J Neurosci Methods 22:147-159.

Hariri AR, Holmes A (2006) Genetics of emotional regulation: the role of the serotonin transporter in neural function. Trends Cogn Sci, in press.

Haughey HM, Kaiser AL, Johnson TE, Bennett B, Sikela JM, Zahniser NR (2005) Norepinephrine transporter: a candidate gene for initial ethanol sensitivity in inbred long-sleep and short-sleep mice. Alcohol Clin Exp Res 29:1759-1768.

Heinz A, Jones DW, Mazzanti C, Goldman D, Ragan P, Hommer D, Linnoila M, Weinberger DR (2000) A relationship between serotonin transporter genotype and in vivo protein expression and alcohol neurotoxicity. Biol Psychiatry 47:643-649.

Heinz A, Goldman D, Gallinat J, Schumann G, Puls I (2004) Pharmacogenetic insights to monoaminergic dysfunction in alcohol dependence. Psychopharmacology 174:561-570.

Jackson BP, Dietz SM, Wightman RM (1995) Fast-scan voltammetry of 5-hydroxytryptamine. Anal Chem 67:1115-1120.

Javitch JA, Strittmatter SM, Snyder SH (1985) Differential visualization of dopamine and norepinephrine uptake sites in rat brain using $\left[{ }^{3} \mathrm{H}\right]$ mazindol autoradiography. J Neurosci 5:1513-1521.

Javors M, Tiouririne M, Prihoda T (2000) Platelet serotonin uptake is higher in early-onset than in late-onset alcoholics. Alcohol Alcohol 35:390-393.

Kranzler H, Lappalainen J, Nellissery M, Gelernter J (2002) Association study of alcoholism subtypes with a functional promoter polymorphism in the serotonin transporter protein gene. Alcohol Clin Exp Res 26:1330-1335.

LeMarquand D, Pihl RO, Benkelfat C (1994) Serotonin and alcohol intake, abuse, and dependence: findings of animal studies. Biol Psychiatry 36:395-421.

Lesch KP, Bengel D, Heils A, Sabol SZ, Greenberg BD, Petri S, Benjamin J, Muller CR, Hamer DH, Murphy DL (1996) Association of anxietyrelated traits with a polymorphism in the serotonin transporter gene regulatory protein. Science 274:1527-1531.

Lin AM, Bickford PC, Palmer MR, Gerhardt GA (1993) Ethanol inhibits uptake of exogenous norepinephrine from the extracellular space of rat cerebellum. Neurosci Lett 164:71-75.

Lin AM, Bickford PC, Palmer MR, Cline EJ, Gerhardt GA (1997) Effects of ethanol and nomifensine on norepinephrine clearance in the cerebellum of young and aged Fischer 344 rats. Brain Res 756:287-292.

Mathews TA, Fedele DE, Coppelli FM, Avila AM, Murphy DL, Andrews AM (2004) Gene dose-dependent alterations in extraneuronal serotonin but not dopamine in mice with reduced serotonin transporter expression. J Neurosci Methods 140:169-181.

McBride WJ, Murphy JM, Gatto GJ, Levy AD, Yoshimoto K, Lumeng L, Li TK
(1993) CNS mechanisms of alcohol administration. Alcohol Alcohol 2:463-467.

McKittrick CR, Magarinos AM, Blanchard DC, Blanchard RJ, McEwen BS, Sakai RR (2000) Chronic social stress reduces dendritic arbors in CA3 of hippocampus and decreases binding to serotonin transporter sites. Synapse 36:85-94.

Miyakawa T, Yagi T, Kitazawa H, Yasuda M, Kawai N, Tsuboi K, Niki H (1997) Fyn-kinase as a determinant of ethanol sensitivity: relation to NMDA-receptor function. Science 278:698-701.

Montañez S, Owens WA, Gould GG, Murphy DL, Daws LC (2003) Exaggerated effects of fluvoxamine in heterozygote serotonin transporter knockout mice. J Neurochem 86:210-219.

Near JA, Bigelow JC, Wightman RM (1988) Comparison of uptake of dopamine in rat striatal chopped tissue and synaptosomes. J Pharmacol Exp Ther 245:921-927.

Nicholson C (1995) Interactions between diffusion and Michaelis-Menten uptake of dopamine after iontophoresis in striatum. Biophys J 68:1699-1715.

Nicholson C, Syková E (1998) Extracellular space structure revealed by diffusion analysis. Trends Neurosci 21:207-215.

Perez XA, Andrews AM (2005) Chronoamperometry to determine differential reductions in uptake in brain synaptosomes from serotonin transporter knockout mice. Anal Chem 77:818-826.

Pistis M, Muntoni AL, Gess G, Diana M (1997) Effects of acute, chronic ethanol and withdrawal on dorsal raphe neurons: electrophysiological studies. Neuroscience 79:171-176.

Rice ME, Nicholson C (1995) Diffusion and ion shifts in the brain extracellular microenvironment and their relevance for voltammetric measurements. In: Voltammetric methods in brain systems (Boulton AA, Baker GB, Adams RN, eds), pp 27-79. Totowa, NJ: Humana.

Roach MK, Davis DL, Pennington W, Nordyke E (1973) Effect of ethanol on the uptake by rat brain synaptosomes of $\left[{ }^{3} \mathrm{H}\right] \mathrm{dl}$-norepinephrine, $\left[{ }^{3} \mathrm{H}\right] 5$ hydroxytryptamine, $\left[{ }^{3} \mathrm{H}\right] \mathrm{GABA}$ and $\left[{ }^{3} \mathrm{H}\right]$ glutamate. Life Sci 12:433-441.

Robinson DL, Lara JA, Brunner LJ, Gonzales RA (2000) Quantification of ethanol concentrations in the extracellular fluid of the rat brain: in vivo calibration of microdialysis probes. J Neurochem 75:1685-1693.

Robinson DL, Volz TJ, Schenk JO, Wightman RM (2005) Acute ethanol decreases dopamine transporter velocity in rat striatum: in vivo and in vitro electrochemical measurements. Alcohol Clin Exp Res 29:746-755.

Shen HW, Hagino Y, Kobayashi H, Shinohara-Tanaka K, Ikeda K, Yamamoto H, Yamamoto T, Lesch KP, Murphy DL, Hall FS, Uhl GR, Sora I (2004) Regional differences in extracellular dopamine and serotonin assessed by in vivo microdialysis in mice lacking dopamine and/or serotonin transporters. Neuropsychopharmacology 29:1790-1799.

Siggins GR, Roberto M, Nei Z (2005) The tipsy terminal: presynaptic effects of ethanol. Pharmacol Ther 107:80-98.

Thielen RJ, Morzorati SL, McBride WJ (2001) Effects of ethanol on the dorsal raphe nucleus and its projections to the caudate putamen. Alcohol 23:131-139.

Thielen RJ, Bare DJ, McBride WJ, Lumeng L, Li T-K (2002) Ethanolstimulated serotonin release in the ventral hippocampus: an absence of rapid tolerance for the alcohol-preferring $\mathrm{P}$ rat and insensitivity in the alcohol-non-preferring NP rat. Pharmacol Biochem Behav 71:111-117.

Thompson MD, Gonzalez N, Nguyen T, Comings DE, George SR, O’Dowd BF (2000) Serotonin transporter gene polymorphism in alcohol dependence. Alcohol 22:61-67.

Virkkunen M, Linnoila M (1997) Serotonin in early onset alcoholism. Recent Dev Alcohol 13:173-189.

Volkow ND, Li T-K (2004) Drug addiction: the neurobiology of behavior gone awry. Nat Rev 5:963-970.

Weinshenker D, Rust NC, Miller NS, Palmiter RD (2000) Ethanol-associated behaviors of mice lacking norepinephrine. J Neurosci 20:3157-3164.

Yaka R, Tang KC, Camarini J, Janak PH, Ron D (2003) Fyn kinase and NR2B-containing NMDA receptors regulate acute ethanol sensitivity but not ethanol intake or conditioned reward. Alcohol Clin Exp Res 27:1736-1742.

Zhou FC, Lesch KP, Murphy DL (2002) Serotonin uptake into dopamine neurons via dopamine transporters: a compensatory alternative. Brain Res 942:109-119.

Zhou FM, Liang Y, Salas R, Zhang L, De Biasi M, Dani JA (2005) Corelease of dopamine and serotonin from striatal dopamine terminals. Neuron 46:65-74 